\title{
The Everyday Experiences of Personal Role Engagement: What Matters Most?
}

\author{
Luke Fletcher
}

\begin{abstract}
Despite increasing interest from the human resource development (HRD) community, little is known about how personal role engagement is experienced in everyday work situations, and which factors are most important for facilitating or thwarting such experiences. A total of 124 employees from six UK organizations were interviewed about the factors that heighten versus reduce their everyday experiences of the emotional, cognitive, and physical aspects of personal role engagement. Template analysis revealed that task, relational, and organizational resources were the most relevant for heightened personal role engagement whereas relational and organizational hindrances were the most prominent for reduced personal role engagement. There was some variation in the salience of task and personal resources as well as challenge demands across organizational settings. Moreover, resources and demands seemed to influence personal role engagement through the psychological conditions of meaningfulness, availability, and, to some degree, safety. This study is one of the first to qualitatively explore the everyday experience of personal role engagement. In doing so, it provides deeper insight into how a HRD approach to engagement can be further advanced with an appreciation of the situational and organizational context.
\end{abstract}

Keywords: employee engagement, work design, employee development, motivation, qualitative research, thematic analysis, comparative research 
Human resource development (HRD) scholars and practitioners have welcomed the concept of employee engagement as an important psychological state that helps translates HRD practices into positive employee outcomes, such as increased performance and retention (Fletcher, 2016; Saks \& Gruman, 2014; Shuck, Twyford, Reio, \& Shuck, 2014). Thus, engagement has been argued to enable "the human spirit to thrive at work" (May, Gilson, \& Harter, 2004, p. 12). However, there is much variation across the discipline in terms of the precise meaning and operationalization of engagement (Shuck, 2011). The concept of engagement first derived from William Kahn's (1990) ethnographic study that examined how people expressed their selves to varying degrees within their work roles. He described engagement as "personal role engagement", which refers to a fluctuating psychological state that, when fully experienced, signifies the simultaneous and authentic expression of one's preferred self during role performances, which manifests emotionally, cognitively, and physically. By utilizing a qualitative approach Kahn (1990) was able to develop a distinct and unique concept of motivation that reflects the 'ebbs and flows' of self-in-role adjustments during the course of a person's working day.

Although research on engagement first originated from, and largely gives reference to, Kahn's (1990) concept of personal role engagement, little research has explicitly focused on Kahn's original conceptualization (Fletcher, 2016; Guest, 2014). Instead, another conceptualization of engagement emerged from research on burnout in the early 2000s, which quickly became adopted by work psychologists. This concept of engagement, labelled 'work engagement', refers to "a positive, fulfilling work-related state of mind that is characterized by vigor, dedication, and absorption...(and) is not focused on any particular object, event, individual, or behavior" (Schaufeli, Salanova, González-Romá, \& Bakker, 2002, p.74). Work engagement is viewed as being highly related to, yet distinct from, 
burnout, i.e. a negative work-related psychological state connoting feelings of emotional exhaustion, cynicism, and depersonalization (Schaufeli et al., 2002), and is now the most dominant concept of engagement in use by academics (Bailey, Madden, Alfes, \& Fletcher, 2015). Its popularity is, in part, because of its accompanying UWES measure (Schaufeli et al., 2002) which has been well-validated across many countries (Scaufeli \& Bakker, 2010), as well as its relatively parsimonious model of antecedents, the job demands-resources (J D-R) model (Bakker \& Demerouti, 2008), which was also originally developed from research on burnout.

However, this over-reliance on the concept and measure of work engagement without fully considering or incorporating Kahn's (1990) original theorizing is somewhat shortsighted and warrants rectification. This is reflected by Roe and Inceoglu (2016, p.73) when they note that engagement "is highly dynamic and allows for many ways of interpretation...(which) raises the question of why Kahn's work was not integrated in the research (on work engagement) by Bakker, Schaufeli and colleagues”. Importantly, the conceptualization of work engagement differs from Kahn's (1990) personal role engagement concept in that it positions engagement as fairly stable attitudinal state and as emphasizing self-employment of energy and commitment to one's work activities (cf Kahn \& Heaphy, 2014; Schaufeli \& Bakker, 2010). This focus on stability and self-employment has been criticized, particularly by HRD and management scholars, as being less substantial and less meaningful than personal role engagement (Cole, Walter, Bedeian, \& O’Boyle, 2012; Fletcher, 2016; Saks \& Gruman, 2014). This is because work engagement seems to a) overlap too much with the concept and construct of burnout and other work attitudes whereas personal role engagement is considered a more distinct motivational concept (Byrne, Peters, \& Weston, 2016; Cole et al., 2012; Saks \& Gruman, 2014); b) focus more narrowly on transactional elements of work activities more so than personal role engagement which 
focused on a broader set of situationally and organizationally embedded elements of work roles (Bargagliotti, 2012; Fletcher, 2016); and c) neglect to fully incorporate the role of personal agency and authenticity of self-expression whereas personal role engagement emphasizes both employment and expression of the self (Kahn \& Heaphy, 2014; Saks \& Gruman, 2014).

Given these criticisms, it is of particular concern that few studies have explored how engagement is experienced in everyday working life across different situations as Kahn (1990) proposed. Later Kahn (2010, p.30) described engagement as "both very delicate and fragile, and quite resilient... it can be broken with a word, said in the wrong way at the wrong time...(yet) engagement (can)...blossom like a malnourished child suddenly fed and loved". Although there are a growing number of quantitative diary studies on work engagement that have started to focus on day-to-day fluctuations (Bakker, 2014), these tend not to examine engagement during discrete situations within the day nor do they consider the full range of potential antecedents (in part due to the quantitative diary methodology employed) or how the salience of these may vary across different organizations. For example, some daily work engagement studies focus on social support such as for teachers (e.g., Simbula, 2010), others focus on management and leadership behaviors for instance within the Navy (e.g., Breevart et al., 2014); another stream test the links between aspects of job design/crafting and engagement such as for teachers (Tadić, Bakker, \& Oerlemans, 2015); and a few examine emotional and personal resources for instance within Universities (e.g., Ouweneel, Le Blanc, Schaufeli, \& Van Wijhe 2012). Therefore, there is no particular way of knowing what situational factors are most important for engagement (and in which organizational settings) nor is there much understanding about the psychological processes involved in translating the work context into the experience of engagement. The present study attempts to address these gaps by qualitatively exploring the work contextual and psychological factors that most 
salient during situations of heightened versus reduced personal role engagement for employees within six different organizational settings. In doing so, this paper will contribute to the engagement literature by developing a richer understanding of personal role engagement that is sensitive to how it is experienced in everyday work situations across different organizational settings.

\section{Personal Role Engagement and Its Situational Antecedents.}

Kahn (1990, p.694) defined engagement as the act of "harnessing...organization members' (preferred) selves to their work roles". Personal role engagement allows individuals to demonstrate 'authenticity', in particular displaying what they think, feel, value, and believe; and aligning this with one's job role (Rich, Lepine, \& Crawford, 2010). When engaged an employee will simultaneously employ and express three core facets of their preferred self: emotional, i.e., feeling a strong positive affective connection to one's work role; cognitive, i.e., feeling particularly attentive and focused at work, and physical, i.e., exerting energy and effort in one's work role (May et al., 2004). A core proposition of personal role engagement theory is that engagement is a transient and fluctuating experience: "people are constantly bringing in and leaving out various depths of their selves (i.e. engagement) during the course of their work days" (Kahn, 1990, p.692). These fluctuations are described as 'self-in-role calibrations', i.e. the individual does not want to feel isolated nor overwhelmed by their job role and so they constantly 'adjust' their investment into their work role accordingly. To fully understand these calibrations "requires deeply probing people's experiences and situations during the discrete moments that make up their work lives" (Kahn, 1990, p.693), thus indicating that engagement should be examined closely in terms of time, place and context. This relates to the qualitative approach to investigating psychological phenomena within organizations (Symon \& Cassell, 2012). Currently less than a handful of studies have examined engagement from a qualitative perspective (e.g., Bakibinga, Vinje, \& Mittelmark, 
2012; Shuck, Rocco, \& Albornoz, 2011), and these are limited due to sampling issues, for example Shuck et al. (2010) sampled three employees from one large multinational company, and because they give little focus to the situational work context of personal role engagement.

Kahn (1990) argued that the experience of personal role engagement is influenced by perceptions of the work context. These derive from one's social and interpersonal interactions, resources and energies, and tasks and roles. Related to this, Kahn (1990) also acknowledged that personal role engagement occurs within complex social systems and that each organization will have particular characteristics unique to that setting. Recently, some scholars have suggested that Kahn's (1990) proposed work context perceptions can be best organized by applying job demands-resources (JD-R) theory (Crawford, Lepine, \& Rich, 2010; Saks \& Gruman, 2014). The JD-R is the framework most often used in explaining the antecedent factors associated with work engagement rather than personal role engagement (Bailey et al., 2015). Essentially, the model differentiates between resources, which serve to heighten engagement through a motivational process, and demands. Demands can either act as challenge demands which energize employees and so heightens engagement, such as challenging work, or hindrance demands, which trigger a health impairment process that reduces engagement, such as abusive supervision or lack of adequate tools (Crawford et al., 2010).

To develop this aspect of the study, Saks and Gruman (2014) as well as the JD-R framework (Bakker \& Demerouti, 2008; Crawford et al., 2010) and theorizing on personal role engagement (Kahn, 1990; Kahn \& Heaphy, 2014) are drawn upon to propose that perceptions of the work context can be categorized into different types of resources and demands based on their level of focus and operation. This paper argues that these different types of resources and demands will be relevant and salient for personal role engagement at the situational level. Given the uncertainty over the 
relative salience of these, an exploratory approach is adopted with the aim of uncovering which demands and resources are particularly relevant to a range of different workers. This study delineates four types of resources: task, organizational, relational and personal.

'Task' resources are motivational features of the various day-to-day tasks that comprise one's job role (Amabile \& Kramer, 2011): varied, challenging, or novel tasks with clear aims and demonstrable outcomes are likely to heighten personal role engagement. Such perceptions act as motivational resources that help one to achieve work goals and foster personal growth (Kahn, 1990; May et al., 2004).

Second, personal role engagement is also likely to vary according to degree to which the individual perceives that they have adequate access to, and availability of, 'organizational' resources, such as the right equipment/information (Crawford, Rich, Buckman, \& Bergeron, 2014). Situations where such resources are easily available will increase personal role engagement as individuals can concentrate on investing these resources into activities that enable productive work-role performances (Kahn, 1990).

'Relational' resources relate to the wider social context and interpersonal relationships at work (Freeney \& Fellenz, 2013) and will likely vary across the working day according to the range of interactions taking place between the employee and their co-workers, manager, and customers/clients (Heaphy \& Dutton, 2008). Kahn and Heaphy (2014) propose that a strong relational context signifies to the individual that they are in a caring and respectful work environment that allows them to express themselves freely, i.e. engage fully, within their work role performances. Management behaviors are included within this category as these mostly involve social interaction with the employee on a daily basis (Breevart et al., 2014).

'Personal' resources refer to a specific aspect of emotional wellbeing and personal agency that comprises perceptions of resiliency and proactivity (Bakker \& Demerouti, 2008; 
May et al., 2004). As personal role engagement concerns the willing investment of one's own energies (Kahn, 1990), it follows that the degree of personal resources that one has at one's disposal will be a key antecedent. These resources enable individuals to enact agentic behaviors that help them to influence their environment (Bandura, 2006). Perceptions of personal resources have been found to fluctuate across and within work days as they are more or less activated by the work context (Xanthopoulou, Bakker, Demerouti, \& Schaufeli, 2012).

Demands refer to a wide range of physical, social and organizational factors. Challenge demands "tend to be appraised as stressful demands that have the potential to promote mastery, personal growth, or future gains" (Crawford et al., 2010, p.836) and as such can heighten engagement. Examples include high workload, time pressure or increased job responsibility. In contrast, hindrance demands "tend to be appraised as stressful demands that have the potential to thwart personal growth, learning, and goal attainment" (Crawford et al., 2010, p.836), thus they act to reduce engagement. In this study, it is proposed that hindrance demands be further differentiated into three types: organizational, relational, and personal. 'Organizational' hindrances focus on disruptions within the physical and structural work environment (Jett \& George, 2003), such as technological breakdowns or overly light or heavy workloads. It also includes conflict/ambiguity within the work environment (Korman, 1971), such as conflicting priorities and unclear plans/procedures. 'Relational' hindrances refer to interpersonal conflict within the social environment such as experiencing negative interactions with customers or experiencing incivility from co-workers/managers (Reio \& Sanders-Reio, 2011; Yang \& Diefendorff, 2009). Lastly, 'personal' hindrances focus on the spill-over effects from the individual's non-work roles and outside lives (Dilworth, 2004; Kahn, 1990), such as experiencing conflict from a spouse/family member or experiencing physical health issues. 
RQ1: What resources and demands are the most salient for heightened versus reduced personal role engagement across different organizational settings?

Kahn (1990) proposed that perceiving positive work environmental conditions would not necessarily foster engagement directly; rather the individual would make a conscious choice, based on these perceptions of the work environment, about whether to engage at a particular moment in time or not. He argued that the individual would make those choices by implicitly answering the following questions: "(1) How meaningful is it for me to bring myself into this performance? (2) How safe is it to do so? and (3) How available am I to do so?" (Kahn, 1990, p.703). In other words, three psychological processes are proposed to be involved in the experience of engagement: psychological safety, availability, and meaningfulness. Although some support for these processes has been found at the betweenperson level using quantitative designs (Chen, Zhang, \& Vogel, 2011; May et al., 2004), there has been little research that has examined these processes in more depth at the situational level. Moreover, the qualitative studies by Shuck et al. (2011) and Bakibinga et al. (2012) found that meaningful experiences arising from the work itself as well as from social interactions facilitated engagement, yet neither examined the full range or depth of the three psychological processes that Kahn (1990) outlined. Therefore, the second research question seeks to clarify how resources and demands influence the everyday experience of engagement, and so will provide greater insight into the psychological foundations of personal role engagement.

$R Q 2:$ How do resources and demands influence the everyday experience of personal role engagement through the psychological conditions of meaningfulness, availability, and safety? 


\section{Method}

\section{Participants and Sample Characteristics}

When designing a qualitative study, it is necessary to identify and utilize an appropriate sampling strategy (Anderson, 2017). Although not explicitly adopting a case study methodology, the logic underlying the selection of 'cases' is still relevant for this study. This is because the study aims to generalize as well as compare the influence of different situational factors on a range of workers. When making these selection decisions, Yin (2009) presents two forms of replication logic that can be used as guiding principles. Replications can be theoretical (i.e. cases produce contrasting results for predictable reasons) or literal (i.e. cases predict similar results). Firstly, applying the theoretical logic, three types of organization that differ in terms of occupational composition and industry sector were selected as previous engagement research indicates that some antecedents of engagement may vary across different occupational groups and industrial sectors (Jenkins \& Delbridge, 2013). Secondly, applying the literal logic, it is useful to have two organizations represented within each of the chosen 'types' of organization. This acts as a form of 'matched-pairing' whereby two organisations with similar profiles regarding structure, employee demographics, and operations represented each organizational 'type'. Therefore, participants were recruited from six medium-sized, UK-based organizations across three sectors: manufacturing, professional services and the public sector.

The lead researcher contacted, via email and briefings, all permanent employees within each organization whereby those interested in taking part in the study contacted the researcher. In order to optimize participation and the spread of different workers, a small cash incentive was used. A total of 151 participants (between 16 and 26 per organization) were recruited onto the study, of whom 124 participated in an interview ( $82 \%$ response rate). $40 \%$ were male, $42 \%$ had managerial responsibility, and $80 \%$ were on full-time contracts. The 
average age was 39.3 years $(S D=11.4)$ and the average tenure to the organization was 9.1 years $(S D=7.9)$. This information is summarized along with a breakdown across the organizations in Table 1. Statistical tests found that none of characteristics varied significantly across the organizations, except age: $F(5,188)=3.83, p<.01$. The subsamples from the councils were, on average, slightly older than those from the other organizations.

\section{INSERT TABLE 1 HERE}

\section{Qualitative Interviews}

Face-to-face semi-structured interviews lasting between 20-40 minutes were audio-recorded and transcribed, with the data being stored and coded within Nvivo 9 (QSR International, 2010). Interviewees were given an operational definition of personal role engagement, drawing on the work by Kahn (1990), Rich et al. (2010) and Shuck (2011), in that engagement refers to a fulfilling psychological experience at work that reflect three related features: a) feeling enthusiastic and positive about your job, b) feeling attentive and focused on your job, and c) feeling energized and wanting to put effort into your job. Interviewees were asked to focus on each of those features in turn and describe to how these aspects varied across their working days. In particular, they were asked to describe situations that tended to a) heighten and b) reduce their levels of those within the context of their working day. They also had recently completed a quantitative work diary focusing on different engagement experiences and so probing questions were asked about the experiences they had encountered during that period and what they had learnt about their engagement within different situations and tasks.

\section{Qualitative Analysis}

Template analysis provides a flexible way to organize, code, and analyze qualitative data thematically and hierarchically (King, 2012). When implementing template analysis, an a- 
priori framework of initial themes based on existing theory is used (Brooks \& King, 2012). This initial 'template' acts as a tentative guide that focuses the analysis towards features that are likely to be of most value, and is modified and re(de)fined as the researcher progresses through the coding of the texts and through continual re-examination of theory and data. In this way the coding process is not just an arbitrary activity, but rather part of the analytical strategy (King, 2012). This process was followed in the current study whereby an initial template based on Kahn's (1990) framework of antecedents (e.g., task characteristics, perceptions of role status and influence, work interactions and interpersonal relations, management style and processes, outside lives) was significantly modified as developments in theory were considered in conjunction with the coding and interpretation of the data. Importantly a decision was made to develop the template in a way that integrated current theoretical advancements emerging during the time of analysis (e.g., Crawford et al., 2010; Saks \& Gruman, 2014) with Kahn's (1990) original framework, i.e. the final categorization of four types of resources and four types of demands. The final template is also refined by hierarchically ordering themes. Higher-order themes give an overview of a feature or category of features, whereas lower-order themes focus on particular features or distinctions within the higher-order theme it is connected to (King, 2012). Figure 1 shows the resultant final template.

As the construct of personal role engagement is a higher-order latent factor (Rich et al., 2010) the coded data from each dimension was aggregated. All the coded references within the interviews were counted, as the unit of analysis was the situation/event. To verify that a particular work condition was associated with a positive or negative impact on engagement, adjectives and descriptions of psychological states in the coded references were analyzed. For example, if an interviewee referred to themselves feeling 'less', 'not very', 'not much' positivity/focus/energy or used adjectives to describe oppositional states such as 
'frustration', then it was inferred that the feature had a negative effect; whereas if an interviewee referred to themselves feeling 'more', 'very' 'lots of' positivity/focus/energy as a result or used adjectives to describe other aspects of such states, such as 'feeling a buzz', then it was inferred that the feature had a positive effect. In addition, each theme was doublechecked to ensure that it impacted on more than one dimension of engagement. Another researcher coded a randomly selected ten per cent of the data in order to test the reliability of the codes. The inter-rater reliability $\kappa$ score for the codes associated with heightened engagement was .76 and .71 for reduced engagement, thus indicating a significant level of agreement: $z=11.04, p<.001 ; z=10.74, p<.001$.

\section{Findings}

The final template for heightened and reduced personal role engagement is given in Figure 1. In the section that follows, illustrative quotes from a range of the interviewees are used.

\section{Heightened Personal Role Engagement}

Task resources. Task resources heightened engagement by providing individuals with a sense of the value and importance of their work tasks to both themselves and to the organization, e.g., "You do take a bit of buzz...because you know that those involved have gotten something out of the service... it's good to see that you are getting that value and gain" (council worker, interviewee 100). In some instances, they also acted as a catalyst for psychological resources to be acquired, particularly tasks that were challenging or novel. In these situations, the individual was energized and motivated to invest resources into their job role in order to gain personal benefits, such as learning a new skill or self-accomplishment, e.g., "it's exciting to throw yourself into it. Part of the challenge is overcoming the problems, which develops your ability and experience" (accountant, interviewee 119). There were two main subthemes: 
Task variety and challenge. This referred to three types of task, which created a sense of variety, challenge and interest: a) skill utilization and problem-solving - tasks that were both intellectually challenging and utilized one's job-related skills and problem-solving abilities, e.g., "When it's a particularly challenging piece of work where I can get my teeth stuck into it...and involves a bit of investigation" (accountant, interviewee 110); b) responsibility and significance to one's self - tasks that had personal significance, particularly in terms of capturing one's interest, and had some degree of personal responsibility/autonomy, e.g., "This was a project that was given to me to do from start to finish with no interference from anybody else... I actually came in early so I could get prepared" (manufacturing worker, interviewee 8); and c) novelty and learning - tasks that were different from the norm and represented an opportunity to learn from experience, e.g., "It's a bit more exciting when you have different things than the usual" (accounts auditor, interviewee 40).

Task clarity and purpose. Tasks that were particularly meaningful in regards to having a wider or deeper significance. This could be achieved in two main ways: a) clarity and significance to others, such that the value and importance to the organization of doing that particular task was clearly highlighted, e.g., "Understanding why you have to do it and the improvements that it's going to make or benefits of doing it to the company...I need to understand why it's important" (manufacturing worker, interviewee 78); and b) personal contribution, such that the task had a visible benefit to self-development, co-workers, or organization, e.g., "When you see something to a conclusion and it has a positive impact... for myself and the team" (council worker, interviewee 100).

Task resources (as well as a lack of these resources - see reduced engagement section) were more frequently discussed by those in the professional services and public sector organizations, than those in the manufacturing organizations. These differences may be due 
to the general design of the occupational roles - those in the manufacturing organizations experienced fairly stable and standardized production routines, e.g., "Most of the things we do are similar challenges or are of similar value...there's never a dull moment I suppose, but it's fairly routine" (production engineer, interviewee 16); whereas those in the professional and public sector organizations experienced more fluidity and variety in their work schedules, especially as many had both external and internal facing duties and responsibilities, e.g., "I think variety helps...it's good to be in a different environment now and again, seeing different people, talking about different things" (accountant, interviewee 42). Therefore, situational fluctuations in task resources may have been more common for professional, rather than manual, occupational groups.

Relational resources. Relational resources in the form of support from supervisors and co-workers reinforced a safe and secure environment, e.g., "It makes me feel that I can always go to my manager and colleagues for help...and that always makes me feel better" (manufacturing worker, interviewee 75). They also helped enhance employees' psychological resources needed for engagement, for example one employee in a council explained how supportive colleagues boosted their energy. Engagement was also enhanced by positive interactions with co-workers and managers when they highlighted the individual's contribution to the organization, e.g., "It makes you feel more positive about you're doing day-to-day and makes you feel that it's worthwhile. It's acknowledgement that you have done a good job" (council worker, interviewee 91). Three specific subthemes emerged:

Perceived supervisory support. This captured three types of behaviors managers enacted during interactions with the individual, which heightened the individual's engagement during the day: a) feedback and recognition - giving positive and constructive feedback; and recognizing or appreciating the individual's efforts, e.g., "Like if I've done something wrong say 'next time remember to do it this way' and when you show 
improvement then say 'you've done that really well'” (manufacturing worker, interviewee 82); b) support and guidance - giving help and support to the individual, particularly giving advice/guidance when the individual faced work-related problems, e.g., "Even though things go wrong, if you get support from a person in a more senior position, and even if they say maybe that isn't the way to do it next time" (council worker, interviewee 49); and c) coaching and developing - enacting empowering behaviors, such as listening and acting on workrelated ideas and issues that the individual had, e.g., "I was in a meeting with a manager...it was more of a problem-solving exercise - this is what we've got at the moment, this is where we want to be, what is the most efficient way of actually doing it" (accountant, interviewee 39).

Perceived co-worker support. This referred to how co-workers heightened the individual's engagement through two types of behaviors: a) support and cooperation particularly during situations of high workloads or interdependence, e.g., "If it involves close team working you pick up energy from the group...you're feeding ideas off each other... there is a buzz around the office" (council worker, interviewee 90); and b) feedback and recognition - acknowledging the individual's efforts, such as giving praise and thanks, e.g., “it's only a couple of words but a thank-you or a well-done goes further than anything else to boost somebody up" (manufacturing worker, interviewee 14). Co-workers could also facilitate engagement through developing a positive and energizing work climate that helped the individual to identify with group goals and values, e.g., "When everyone comes out of a meeting with a positive outlook and knows what the goals and aims are going to be...everyone is in it together" (council worker, interviewee 89).

Customer/client interactions. This subtheme related more so to those in direct customer-facing roles. Customers and clients could heighten engagement: a) co-operation when they cooperated well with and were friendly towards the employee, and it was clear 
how the employee could help them, e.g., "When a client comes in needing help and you can see how you can help them and what you can do...the feeling that you've helped someone and it makes the firm look good" (accountant, interviewee 122); and b) positive feedback - when they gave the employee positive praise and feedback about the work they had done, the advice/information they had given, or the overall service they had provided, e.g., "Being thanked by the (customer) for your help, for taking the time to listen... you feel a sense of satisfaction and it's quite rewarding when you know that you have helped that person" (council reception/customer service worker, interviewee 67).

Relational resources were the most similar in depiction and discussion across the organizational settings; although the salience of the line manager versus co-workers depended upon how interdependent the individual's work role was in relation to their workgroup as well as the overall managerial style and disposition of the line manager.

Organizational resources. This encompassed the use of planning tools, such as to-do lists and scheduling personal goals in order to prioritize tasks, as well as making choices regarding when to utilize available organizational resources within the day. Although these strategies served primarily to provide energy and internal resources for engagement, e.g., "You may be a bit more energized and you come back and try and tackle all things you haven't done" (accountant, interviewee 25), being able to plan and progress also gave the individual a fuller sense of task achievement and accomplishment, e.g., "It had all started to make sense, and you could see what was going to happen" (manufacturing worker, interviewee 17). Two subthemes were identified:

Planning and progress. This referred to the ways in which the individual could feel a sense of achievement and self-efficacy through planning/structural resources. There were two aspects to this: a) prioritization - when the individual was able to successfully prioritize and structure their tasks to better suit their workloads or in a way that enacted goal setting 
techniques, e.g., "Making lists and setting deadlines...it's a challenge...So you feel quite pleased with yourself if you can come up with a plan and achieve that plan" (council worker, interviewee 44); and b) achieving progress - when the individual perceived or was able to achieve progress by completing tasks or meeting goals within the day, e.g., "I was able to meet the targets for the day and get all the important tasks done early. It was about achieving what I needed to get done" (manufacturing worker, interviewee 76).

Self-regulation and recovery within work. This referred to the ways in which the individual maintained control over and coped with the demands of work through the utilization of organizational resources. This involved three main actions: a) breaking up the day - through choosing to have 'down-time' by completing routine tasks and by taking regular breaks that involved physical exercise/mental relaxation, e.g., "I need to take a break where I have a wander outside in the early afternoon and get some fresh air" (accountant, interviewee 93); b) utilizing flexible working practices/tools - to influence their environment when there was a need to prevent distractions, e.g., "When I'm doing harder tasks where I need to be really involved in it and block everything else out I use a red sign - (it signals to others) that I need to not be disturbed" (administrator, manufacturing, interviewee 107); and c) physiological regulation - ensuring that basic needs were fulfilled throughout the day, e.g., "After I've had some food or a teabreak I'm straight back up - I'm not worried about anything, I'm happy as larry" (manufacturing worker, interviewee 13).

The degree of personal discretion and control over these actions varied across the organizational settings; with the manufacturing workers having the least flexibility and needing to negotiate more with managers than the professional services and council workers.

Challenge demands. Challenge demands, in the form of challenges from workloads and work pressures, heightened personal role engagement by providing a sense of purpose and achievement, e.g., "I'm more driven and motivated by it. You get a better feeling from 
that- it feels like you're achieving things" (council worker, interviewee 60). Two key elements were discussed: a) a sense of urgency and time pressure, which acted as a source of energy that increased engagement, e.g., "the adrenaline kicks in and keeps you going. It's not something that you really think about, you just do it" (manufacturing worker, interviewee 2); and b) a sense of regularity and certainty of workload - that provided a predictable environment, e.g., "Not crazily busy but busy enough that you're...automatically thinking about getting things right" (accountant, interviewee 108).

Challenge demands were more frequently discussed by those in the professional services and manufacturing organizations than those in the public sector organizations. This may have been in part due to the nature of bureaucracy prevalent in public sector organizations. Many from these organizations discussed how much of their work was governed and shaped by decision-making committees, councillor interests and agendas, and central government mandates. Thus, the time pressure and sense of urgency was not necessarily as prevalent for these individuals due to waiting and processing of information, decisions and actions, yet this could make some periods within the week time pressured and urgent due to a sudden shift in workloads and priorities, e.g., "You'll have a number of days where it's extremely busy with a number of key meetings, issues, deadlines, and then you'll have a number of days where you're working towards future things or waiting for decisions to be made" (council worker, interviewee 59)

Personal resources. Personal resources were salient for situations of heightened engagement when the individual was focused on developing feelings of competence. Some individuals actively sought out opportunities that allowed them to feel self-efficacious and competent in their jobs, e.g., "It made me much more aware of what I was doing and it just made me feel a lot more confident - I could help out my manager in the future" (manufacturing worker, interviewee 1). 
These resources were more frequently discussed by those in the manufacturing organizations than those in the other types of organization. This may have been partly due to the scheduling of work and organization of the production process in the manufacturing organizations. In contrast to those in the professional services and public sector organizations, many employees in the manufacturing organizations worked shifts, had little control over their work schedules, and were heavily interdependent with other groups/departments in the organization. Therefore, to cope with this lack of personal autonomy and to maintain personal role engagement, some interviewees from the manufacturing organizations described how they would come in with a 'mindset' that helped them be more resilient and self-efficacious, e.g., "I tried to come in with a mental picture in my head of what I was going to be doing throughout the day.... a kind of mindset. Once I was in the right attitude then it kind of stayed like that- it helped to keep my (engagement) more constant and stable" (manufacturing worker, interviewee 3).

\section{Reduced Personal Role Engagement.}

Relational hindrances. Relational hindrances made the individual feel disrespected and less secure about their role in the wider work group, which reduced engagement, e.g., "I have ideas to improve things but sometimes I don't feel valued...because co-workers or managers don’t listen to your ideas" (manufacturing worker, interviewee 83).

From line managers. This captured four specific behaviors that managers enacted during interactions with the individual (the first two focus on a lack of support where the latter two focus more on incivility): a) unclear expectations of performance - when the manager did not give clear or precise information regarding the standards required, and did not give adequate guidance, e.g., "Today I've been told to do a project, which I've never done anything like that before... I've just been told to use my common sense... it can be a bit disheartening" (council worker, interviewee 54); b) restrictive practices - that limited the 
individual's autonomy, involvement or responsibility; often involving poor decisions regarding delegation or prioritization of tasks; micro-managing, and not involving the individual in decisions or discussions, e.g., "my manager sometimes can be too prescriptive...I haven't had any input... that's when you feel like you're going through the motions" (council worker, interviewee 103); c) undermining behaviors - that explicitly disrespected the individual, e.g., "when a team leader come overs and says 'you can't do that job, you can't keep up' and everybody on the line hears and then you feel 'if I'm that worthless to you then wherever you stick me today that's the (negative and 'can't be bothered') kind of attitude you're going get"' (manufacturing worker, interviewee 13); and d) aggressive/dismissive communication style - when the manager demanded the employee to do a task, and was perhaps quite aggressive or dismissive in tone, e.g., "demanding you do something without asking you (or) has said something in a way that is quite aggressive... sometimes bluntness can come across as rudeness" (personal assistant, professional services, interviewee 109)

From co-workers. This referred to how co-workers decreased the individual's engagement through four types of behavior (the first focuses on a lack of support, the second focuses on incivility, and the third and fourth focus on social dynamics): a) reluctance to help - when co-workers were unable to give support or were uncooperative during times of high demands, e.g., "I asked a colleague to help me, but they did not, and I felt frustrated, disheartened and slightly angry...I would never have done that to them" (accountant, interviewee 22); b) poor feedback/lack of recognition - when co-workers gave unconstructive/negative feedback, or did not recognize/appreciate the efforts the individual had given, e.g., "I will get no recognition for doing that (work for my colleagues) - that's annoying” (manufacturing worker, interviewee 8); c) negative group climate - when coworkers created a negative work environment by being outwardly apathetic, hostile or 
frustrated, e.g., "Co-workers apathy towards your work...you can get a little bit despondent and less enthusiastic - you've put time and energy into making something work" (council worker, interviewee 55); and d) violation of group norms - when co-workers were perceived to be not pulling their weight or not being committed to tasks, such that they violated shared values and norms, e.g., "It was a lack of effort on their (co-worker's) side which was annoying. Why am I exerting myself when they aren't even bothering? It makes me less enthusiastic and more wound up" (manufacturing worker, interviewee 6)

Negative customer/client interactions. For those who had some level of customer/client interaction within everyday working life, customers/clients could decrease engagement a) lack of co-operation - in terms of not giving the right information or not listening to advice, e.g., "If you've got a really difficult client to deal with it's hard to think I'm going to do my upmost" (accountant, interviewee 115); or b) poor feedback - when they gave negative feedback to the employee that made the individual feel that they had not done a good job, e.g., "When I get negative feedback...you let a customer down" (sales administrator, manufacturing, interviewee 74).

Similarly to relational resources, relational hindrances were fairly similar in depiction and discussion across the organizational settings; with the salience varying dependent upon the level of interdependence and managerial style. Poor managerial behaviour was perhaps more discussed by those in the manufacturing organizations, and this may be due to the fact that these organizations, compared with the others, did not have a formal human resource management function and so managers were often inconsistently trained with regards to providing good people management.

Organizational hindrances. The second main factor was organizational hindrances, which reduced the replenishment of energies and resources needed to sustain engagement. A core aspect was feeling unable to control or have any direct influence over the situation, e.g., 
"You're fighting the fires... it isn't working and you're not getting anywhere... I suppose it's a lack of control" (accountant, interviewee 107). As such, these demands hindered the ways in which job tasks could provide a sense of worth and value as tasks were often disrupted, e.g., "Everything just becomes a bit more of a struggle... because you don't feel that empowered" (manufacturing worker, interviewee 19). There were two main subthemes:

Hindrances from the physical environment, systems and processes. The structural and systemic features of the work environment reduced engagement through: a) distractions particularly when environment was noisy, disruptive and chaotic, e.g., "If it's a busy room...with noise and people asking you for stuff...I find it quite hard because you just want to block everything out and you can't" (accountant, interviewee 28); b) inefficiencies or breakdowns in (technological) systems - particularly those used to complete core work tasks, e.g., "I was hampered with software problems so I couldn't hardly do anything. That was very frustrating because I had a deadline to meet, which had to be shunted back because I couldn't physically do it...I didn't achieve anything and the issue wasn't resolved" (council worker, interviewee 102); and c) inefficiencies or breakdowns in decision-making processes particularly where breakdowns in communication or the flow of information prevented tasks from being completed, e.g., "Sometimes...it's out of our control...we got an email yesterday about a job that needs to go out next week and they wanted us to start running it today, but...that could not be achieved... it didn't get noticed until we started running behind" (manufacturing worker, interviewee 80).

Hindrances from workloads and work pressures. Perceived workloads and work pressures demanded from the organization reduced engagement when: a) excessive and conflicting demands - these contributed to the individual feeling overwhelmed and bombarded, e.g., "I can get pulled in all sorts of directions...you can quite easily end up not really doing anything" (accountant, interviewee 107); and b) having too little workloads and 
demands - these contributed to the individual feeling de-motivated and de-energized, e.g., "When you're not busy it's harder...you're not that sure what's expected. You relax a bit, and become a bit laid back and the day goes slowly and there seems to be more problems" (manufacturing worker, interviewee 81).

The relevance and salience of organizational hindrances did not vary to a great extent across the organizational settings, although they were slightly more pronounced in the manufacturing organizations due to the high interdependence and reliance on the overall production systems and scheduling processes. The councils and professional services organizations were more affected by decision-making processes and IT/computer breakdowns, which reflects that these types of organization are more knowledge intensive and politically bureaucratic in nature.

Personal hindrances. Personal hindrances related to the individual's non-work roles, personal health/wellbeing and self-consciousness that negatively affected engagement during the workday. These impaired the individual's ability to engage by distracting attention away from the job role or by reducing the desire to invest efforts into the job role as benefits from investing energies were less clear or immediate, e.g., "It makes you feel 'why am I doing this' and you just want to go home" (manufacturing worker, interviewee 74). There were three main ways that personal hindrances could arise:

From non-work roles. Engagement was depleted when the individual was experienced significant events or issues within their outside life, particularly for those with families or caring responsibilities, e.g., "A member of the family has health issues...(I'm) not so good some mornings" (council worker, interviewee 63).

From one's personal health and wellbeing. Engagement was difficult to muster when the individual felt in ill mental, emotional or physical health e.g. "It's a bit of 
struggle...when you're really tired or if you don't feel very well" (manufacturing worker, interviewee 21).

From feeling insecure and self-conscious. Engagement was reduced when the individual perceived that they had made an unnecessary mistake or had failed to meet expectations or personal goals, e.g., "If I find that I've made mistakes - especially when they're silly mistakes and I know that I shouldn't have made them" (manufacturing worker, interviewee 76).

Personal hindrances did not vary in any significant way across the organizational settings, yet there may be significant individual differences that cannot be fully examined in this study.

Lack of task and organizational resources. Finally, absence of two forms of resources, task resources and organizational resources also contributed to reduced engagement. A lack of task and organizational resources limited the perceived worth and purpose of tasks, e.g., "I can't see there's any point to it (the task) so I don't feel valued" (manufacturing worker, interviewee 83), the ability to derive meaning from the work environment, e.g., "Sometimes you go around in circles and you think "why am I here?" (council worker, interviewee 44), and the availability of energies needed to fully engage, e.g., "My energy levels drop a bit because you relax a bit more and you're plodding along" (accountant, interviewee 105). Three subthemes emerged (first related to task resources and other two related to organized resources):

A lack of task variety and challenge. Two elements were discussed in relation to having a lack of varied and challenging work tasks within the workday: a) a feeling of boredom - due to tasks that lacked mental stimulation and had become too 'routine and mundane', e.g., "(the task was) a bit monotonous and a bit boring. When you have done 
something over and over it becomes very routine, very mundane and there's no new challenges in that task" (council worker, interviewee 55); and b) feelings of psychological disconnection - due to tasks that were misaligned from the core job role and as such did not adequately fulfil what the individual desired from the job, e.g., "It's dealing with paperwork, essentially you are processing figures, completing paperwork and passing it onto somebody else...So it's a little bit disconnected from the human aspect" (accountant, interviewee 29).

An inability to plan and prioritize tasks. Engagement was reduced, particularly during high demands, when there was restricted access/availability to plan and to accommodate unexpected events, e.g., "I had set out a four-hour chunk (to concentrate on one particular task). But I had three impromptu meetings about different things...because it wasn't planned it spoilt the day...it wasn't something that I had hoped to achieve (manufacturing worker, interviewee 76).

An inability to self-regulate energies. Engagement was difficult to maintain when there were limited opportunities to take breaks and to reenergize after difficult tasks, e.g., "Because of the nature of the work sometimes I work through my lunchbreak and so I feel it's more difficult to maintain my energy (and enthusiasm) towards the end of the day" (council worker, interviewee 112).

As discussed earlier, a lack of task resources was discussed most by those in the professional services and public sector organizations. No significant variation was found across the organizational settings regarding lack of organizational resources.

INSERT FIGURE 1 HERE 


\section{Discussion}

Although there is increasing interest in the concept and application of engagement to the HRD community over recent years (Saks \& Gruman, 2014), there still remains a lack of understanding of Kahn's (1990) original concept of personal role engagement. Therefore, the present study sought to examine the everyday experience of personal role engagement by drawing on qualitative data from 124 employees across six UK organizations. Overall, this study connects Kahn's (1990) personal role engagement theory with the widely adopted J DR model (Bakker \& Demerouti, 2008) by showing how personal role engagement is heightened by certain resources and demands and reduced by specific hindrances within the task, relational, and organizational environment. This empirically addresses recent calls within the HRD discipline for research that brings together these two theoretical perspectives (Saks \& Gruman, 2014). In doing so, it provides a more nuanced model of antecedents that considers the situational and organizational context. This will help to alleviate concerns that engagement research is too acontextual to be of use to practitioners (Purcell, 2014), and provides opportunities within the HRD community to advance a situationally sensitive, pragmatic approach to understanding of personal role engagement.

The first research question focused on identifying and differentiating the work conditions that are most relevant and salient during situations of heightened versus reduced personal role engagement. Many of the work conditions that heightened personal role engagement within everyday work situations were found to be qualitatively different to those that reduced it, yet both types of experience were influenced mainly by the relational and organizational context. In particular, the behavior and actions of co-workers and managers as well as the management practices surrounding organizational systems and processes could heighten or reduce personal role engagement. This highlights the importance of a holistic HRD approach to facilitating engagement that considers how HRD practices need to be 
embedded within, and consider the complexities, of workgroup and managerial practices/processes (Shuck \& Rocco, 2014).

Additionally, the study underscores the engaging potential of task resources and challenge demands: varied, challenging, and purposeful tasks with a sense of urgency and regularity particularly heightened personal role engagement. However, the salience of task resources and challenge demands varied across the organizational settings. Personal role engagement for those in 'professional' occupations may be more sensitive, compared with 'manual' occupations, to changes in the nature and design of work tasks due to their roles being generally more varied and less fixed by organizational structures and processes. This corresponds with work design theorists who argue that the salience of different work characteristics will vary according to the nature of the occupational context (Morgeson, Dierdorff, \& Hmurovic, 2010). In this case, the salience of job variety, challenge and clarity to increasing personal role engagement may be particularly pronounced for those in professional occupations. Furthermore, employees in public sector organizational structures may be less likely to perceive demands as challenges due to decision-making structures that make time pressure and urgency less salient, whereas employees working in traditional production organizational structures are likely to enact attitudinal/behavioral strategies to sustain high levels of personal role engagement due to the lack of autonomy/control imposed by the structural environment. These findings therefore suggest that structural interdependence and uncertainty are important contextual features that shapes how work role performances, via personal role engagement, are expressed and evaluated (Griffin, Neal, \& Parker, 2007). The study also demonstrated the disengaging potential of personal hindrances: significant family events or responsibilities could distract the individual away from their job, thus reducing personal role engagement. This raises the importance of examining the 
interface between work and non-work roles, and how these are negotiated and managed by the individual to maintain their engagement across multiple roles.

Bringing these findings together suggests that different types of resources and demands have varying influences on personal role engagement, thus supporting and extending prior research that has sought to further refine the J D-R model (Crawford et al., 2010; Saks \& Gruman, 2014). Moreover, they highlight the need to understand the relationships between resources, demands, hindrances, and personal role engagement in more depth at the situational level. For example, many of the organizational hindrances that reduced engagement in this study may reflect what Jett and George (2003) refer to as environmental 'irritations'. However, Jett and George (2003) also argue that some distractions may actually have a functional purpose to reduce organizational hindrances, and therefore distractions may have some potential to protect personal role engagement in certain situations. Another aspect to consider is the degree to which the employee can structure their workday to enact activities that serve to heighten personal role engagement. Elsbach and Hargadon (2006, p.475) propose that a scheduled form of 'mindless' work, i.e. "tasks that are low in cognitive difficulty and performance pressures" such as simple administration, maintenance or service tasks, can help to foster creativity through fulfilling psychological needs.

The second research question focused on understanding how resources and demands heightened or reduced personal role engagement. The findings revealed that task resources influenced personal role engagement through meaningfulness by highlighting the value of their work to themselves and to others within the organization, as well as through developing and expressing their potential. This latter aspect also facilitated psychological availability as such resources enabled self-enhancement and accomplishment, thus raising one's perceived capability to engage. A lack of task resources, in contrast, placed limits on these processes. 
These effects were somewhat similar for (lack of) organizational resources in that they heightened (reduced) personal role engagement through facilitating (placing limits on) the development of psychological resources, such as resilience, the self-regulation of energy, and one's sense of task meaningfulness. Organizational hindrances acted to disrupt these processes and direct energies away from effective work role performances. A critical characteristic underpinning the effects of organizational resources/hindrances was the perception of control and personal agency; resources strengthened this perception whereas hindrances eroded it. Relational resources influenced personal role engagement by maintaining and reinforcing a psychologically safe and rewarding social environment, whereas relational hindrances violated perceptions of safety and threatened social relations that had been developed. Moreover, meaningfulness and availability were also involved for relational resources, which strengthened a sense that one, as a person, has value and worth to others in the organization, and boosted energy as well as self-efficacy and self-esteem. Challenge demands and personal resources raised personal role engagement by promoting availability through creating energies needed for persistence, and by facilitating meaningfulness through providing a sense of purposeful endeavour. In contrast, personal hindrances depleted energies needed for personal role engagement, and caused some questioning of the value of their work tasks when other (more important) things were happening in their lives. Overall, these findings show support for Kahn's (1990) psychological conditions framework as meaningfulness and availability, and to some degree safety, were involved in linking resources and demands with personal role engagement. However, as indicated in Figure 2, they also suggest that Kahn's (1990) framework needs modification and further development, particularly with clarifying the boundaries between, and synergistic properties of, the three psychological conditions. 
INSERT FIGURE 2 HERE

\section{Implications for HRD Scholarship and Practice}

The findings of this study have several implications for the HRD scholarly and practitioner communities. The first implication is in regards to the situational and temporal nature of engagement. HRD research on, and practical approaches to, engagement should focus on developing a more contextualized understanding of the experience of personal role engagement that considers changes over time and place. For example, how does engagement change as a result of an HRD initiative, and how can the transfer of learning be optimized for the day-to-day experiences of engagement? Additionally, drawing on Kahn's (1990) idea of self-in-role calibrations, it would be of interest to explore the ways in which HRD practices could enable individuals to navigate the boundaries between work and non-work roles in their everyday lives and what learning and coping strategies might be best placed to achieve a healthy productivity.

The second implication is focused on understanding the managerial, group, and organizational practices that HRD can influence in order to protect, sustain, and raise engagement. The findings of this study reveal that engagement is heightened or reduced according to the presence of particular resources and demands, which the HRD practitioner could influence. HRD scholars and practitioners could, in particular, explore three main HRD practices. One is focused around developing line manager coaching and mentoring so that they are empowered and have the skills necessary to provide support, constructive feedback, and recognition as well as to help create an energizing and friendly social environment through knowing when/how to reward positive forms of social support and expressions of engagement, and conversely when/how to respond to acts of incivility within the workgroup. 
Another is about designing team development initiatives that strengthen relational resources by providing opportunities to share knowledge and learning experiences within the workgroup, and personal development activities that build personal resources through providing opportunities to utilize their personal agency, proactivity, and creativity/skills. The final practice involves shaping work (re)design and organizational development initiatives in ways that help individuals and teams to identify 'functional' interruptions and ways in which to best structure their workdays, as well as to strengthen their ability to change and negotiate elements of their job, and how they are performed. However, the findings of the study also underscore the need to understand the organizational setting as the relative salience of resources and demands may vary across different organizations. Therefore, HRD practitioners looking to facilitate personal role engagement within their organizations should be cognizant of broader occupational (and structural factors (e.g., extent of customer interactions, independence within and between workgroups, bureaucracy of decision-making processes, dependence on technological systems) that may change the scope and reactions to these practices.

Finally, the third implication is about advancing our understanding of the psychological processes involved in the experience of engagement, and how HRD practitioners can leverage these processes within specific strategies and initiatives. This study indicates, as Kahn (1990) proposed, that meaningfulness, availability, and safety are important psychological processes involved in connecting resources and demands in the situational work context with the experience of personal role engagement. Given that these psychological concepts have evolved since Kahn's (1990) study, it is recommended that HRD scholars focus on integrating these literatures. For example, Edmondson's (1999) theorizing on team psychological safety and Luthans, Avolio, Avey, \& Norman's (2007) work on psychological capital could be utilized, and the work of Lips-Wiersma and Wright 
(2012) could be a useful way of advancing Kahn's notion of meaningfulness as they have distinguished between four dimensions: unity with others, service to others, expressing full potential, and developing/becoming self. These also have important implications for HRD practice, particularly as these could provide useful frameworks for design and evaluation. For example, HRD practitioners could develop key strategic aims or performance-related indicators based around meaningfulness (e.g., do employees feel that their sense of worth and value to the organization is strengthened as a result?), availability (e.g., do employees feel they have more energy and resilience as a result?), and safety (e.g., do employees feel they are able to voice their concerns or ideas in their workgroup as a result?). Therefore, this study reveals fruitful avenues to develop Kahn's (1990) framework within the HRD community.

\section{Limitations}

There were time restrictions due to the requirements for participants to complete other research activities, and so the interview guide was used more rigidly than anticipated. Therefore, the opportunity to examine the concepts, and relationships between them, more deeply through broader discussions was somewhat limited. To further examine potential relationships, future qualitative researchers may want to adopt a critical incident technique (Chell, 2004). Related to this, further quantitative testing of Kahn's (1990) personal role engagement theory could clarify to what extent the psychological conditions of meaningfulness, availability and safety are involved in linking the resources, demands, and hindrances found in this study to the everyday experience of engagement. Moreover, although the study considered, to some degree, the organizational context, individual differences and demographic characteristics were not fully investigated. For example, many quantitative studies on engagement control for the potential effects of age and gender (e.g., Fletcher, 2016), and therefore there might be scope to qualitatively explore how these individual characteristics may shape the experience of personal role engagement. Lastly, it is 
acknowledged that a realist approach was undertaken to analyze and interpret the interview data. Future research that takes an alternative analytical perspective, for example from a critical management perspective, would therefore be welcome. In particular, as George (2011) and Purcell (2014) argue, it would be of interest to explore the potential tensions and power dynamics that occur when employees utilize personal strategies to exert control and influence over their personal role engagement.

\section{Conclusion}

To conclude, the current study sought to qualitatively examine the everyday situational experiences of personal role engagement and identify the factors that are most important for such experiences. The paper connects Kahn's (1990) personal role engagement theory with the J D-R model (Bakker \& Demerouti, 2008) by differentiating the impact and influences of four types of resources (task, organizational, relational, personal) and four types of demands (challenge, organizational hindrances, relational hindrances, personal hindrances) at the situational level. The findings reveal that task, organizational and relational resources particularly heighten personal role engagement, whereas organizational and relational hindrances significantly reduce the experience of personal role engagement. Moreover, the paper affirms Kahn's (1990) view that key psychological processes act to connect the work context with the experience of personal role engagement. Overall, the findings suggest ways in which HRD practitioners can facilitate personal role engagement through promoting psychological meaningfulness, availability, and safety. 


\section{References}

Amabile ,T.M., \& Kramer, S.J. (2011). The power of small wins. Harvard Business Review, 89, 72-80. ISSN: 0017-8012

Anderson, V. (2017). Criteria for evaluating qualitative research. Human Resource Development Quarterly. Epub ahead of print. doi: 10.1002/hrdq.21282

Bailey, C., Madden, A., Alfes, K., \& Fletcher, L. (2015). The meaning, antecedents and outcomes of employee engagement: A narrative evidence synthesis. International Journal of Management Reviews. Epub ahead of print. doi: 10.1111/ijmr.12077

Bakibinga, P., Vinje, H.F., \& Mittelmark, M.B. (2012). Self-tuning for job engagement: Ugandan nurses' self-care strategies in coping with work stress. International Journal of Mental Health Promotion, 14, 3-12. doi: 10.1080/14623730.2012.682754

Bakker, A. B. (2014). Daily fluctuations in work engagement. European Psychologist, 19, 227-236. doi: 10.1027/1016-9040/a000160

Bakker, A.B., \& Demerouti, E. (2008). Towards a model of work engagement. Career Development International, 13, 209-223. doi:10.1108/13620430810870476

Bandura, A. (2006). Toward a psychology of human agency. Perspectives on Psychological Science, 1, 164-180. doi: 10.1111/j.1745-6916.2006.00011.x.

Bargagliotti, L. A. (2012). Work engagement in nursing: A concept analysis. Journal of Advanced Nursing, 68, 1414-1428. doi: 10.1111/j.1365-2648.2011.05859.x

Breevaart, K., Bakker, A.B., Hetland, J., Demerouti, E., Olsen, O.K., \& Espevik, R. (2014). Daily transactional and transformational leadership and daily employee engagement. Journal of Occupational and Organizational Psychology, 87, 138-157. doi: 10.1111/joop. 12041 
Brooks, J. and King, N. (2012). Qualitative Psychology in the Real World: The Utility of Template Analysis. Presented at British Psychological Society Annual Conference, 18th - 20 ${ }^{\text {th }}$ April 2012, London, UK. Available from at http://eprints.hud.ac.uk/13656/ [Accessed January 2017]

Byrne, Z. S., Peters, J. M., \& Weston, J. W. (2016). The struggle with employee engagement: Measures and construct clarification using five samples. Journal of Applied Psychology, 101, 1201-1227. doi: 10.1037/ap10000124

Chell, E. (2004). Critical incident technique. In C. Cassell \& G. Symon (Eds.), Essential Guide to Qualitative Methods in Organizational Research (pp. 45-60). London: Sage Publications.

Chen, Z., Zhang, X., \& Vogel, D. (2011). Exploring the underlying processes between conflict and knowledge sharing: A work-engagement perspective. Journal of Applied Social Psychology, 41, 1005-1033. doi: 10.1111/j.1559-1816.2011.00745.x

Cole, M.S., Walter, F., Bedeian, A.G., \& O’Boyle, E.H. (2012). Job burnout and employee engagement: A meta-analytic examination of construct proliferation. Journal of Management, 38, 1550-1581. doi: 10.1177/0149206311415252

Crawford, E.R., Lepine, J.A., \& Rich, B.L. (2010). Linking job demands and resources to employee engagement and burnout: A theoretical extension and meta-analytic test. Journal of Applied Psychology, 95, 834-848. doi: 10.1037/a0019364

Crawford, E.R., Rich, B.L., Buckman, B., \& Bergeron, J. (2014). The antecedents and drivers of employee engagement. In C. Truss, R. Delbridge, K. Alfes, A. Shantz, \& E. Soane (Eds.), Employee Engagement in Theory and Practice (pp. 57-81). London: Routledge.

Dilworth, J. E. L. (2004). Predictors of negative spillover from family to work. Journal of Family Issues, 25, 241-261. doi: 10.1177/0192513X03257406 
Edmondson, A. (1999). Psychological safety and learning behavior in work teams.

Adninistrative Science Quarterly, 44, 350-383. doi: 10.2307/2666999

Elsbach, K.D., \& Hargadon, A.B. (2006). Enhancing creativity through "mindless" work: A framework of workday design. Organization Science, 17, 470-483. doi: $10.1287 /$ orsc. 1060.0193

Fletcher, L. (2016). Training perceptions, engagement and performance: Comparing personal role engagement and work engagement. Human Resource Development International, 19, 4-26. doi: 10.1080/13678868.2015.1067855

Freeney, Y., \& Fellenz, M.R. (2013). Work engagement, job design and the role of the social context at work: Exploring antecedents from a relational perspective. Human Relations, 66, 1427-1445. doi: 10.1177/0018726713478245

George, J.M. (2011). The wider context, costs, and benefits of work engagement. European Journal of Work and Organizational Psychology, 20, 53-59. doi: $10.1080 / 1359432 X .2010 .509924$

Griffin, M.A., Neal, A., \& Parker, S.K. (2007). A new model of work role performance: Positive behavior in uncertain and interdependent contexts. Academy of Management Journal, 50, 327-347. doi: 10.5465/AMJ.2007.24634438

Guest, D.E. (2014). Employee engagement: A sceptical analysis. Journal of Organizational Effectiveness: People and Performance, 1, 141-156. doi: 10.1108/JOEPP-04-20140017

Heaphy, E. D., \& Dutton, J. E. (2008). Positive social interactions and the human body at work: Linking organizations and physiology. Academy of Management Review, 33, 137-162. doi: 10.5465/AMR.2008.27749365 
Jenkins, S., \& Delbridge, R. (2013). Context matters: Examining 'soft' and 'hard' approaches to employee engagement in two workplaces. The International Journal of Human Resource Management, 24, 2670-2691. doi: 10.1080/09585192.2013.770780

Jett, Q.R., \& George, J.M. (2003). Work interrupted: A closer look at the role of interruptions in organizational life. Academy of Management Review, 28, 494-507. doi: 10.5465/AMR.2003.10196791

Kahn, W.A. (1990). Psychological conditions of personal engagement and disengagement at work. Academy of Management Journal, 33, 692-724. doi:10.2307/256287

Kahn, W.A. (2010). The essence of engagement: lessons from the field. In S.L. Albrecht (Ed.), Handbook of Employee Engagement: Perspectives, Issues, Research and Practice (pp. 20-30). Cheltenham, UK: Edward Elgar.

Kahn, W.A., \& Heaphy, E.D. (2014). Relational contexts of personal engagement at work. In C. Truss, R. Delbridge, K. Alfes, A. Shantz, \& E. Soane (Eds.), Employee Engagement in Theory and Practice (pp. 82-96). London: Routledge.

King, N. (2012). Doing template analysis. In G. Symon \& C. Cassell (Eds.), Qualitative Organizational Research: Core Methods and Current Challenges (pp. 426-450). London: Sage Publications.

Korman, A. K. (1971). Environmental ambiguity and locus of control as interactive influences on satisfaction. Journal of Applied Psychology, 55, 339-342. doi: $10.1037 / \mathrm{h} 0031470$

Lips-Wiersma, M., \& Wright, S. (2012). Measuring the meaning of meaningful work development and validation of the Comprehensive Meaningful Work Scale (CMWS). Group \& Organization Management, 37, 655-685. doi:

$10.1177 / 1059601112461578$ 
Luthans, F., Avolio, B. J., Avey, J. B., \& Norman, S. M. (2007). Positive psychological capital: Measurement and relationship with performance and satisfaction. Personnel Psychology, 60, 541-572. doi: 10.1111/j.1744-6570.2007.00083.x

May, D.R., Gilson, R.L., \& Harter, L.M. (2004). The psychological conditions of meaningfulness, safety and availability and the engagement of the human spirit at work. Journal of Occupational and Organizational Psychology, 77, 11-37. doi: $10.1348 / 096317904322915892$

Morgeson, F.P., Dierdorff, E.C., \& Hmurovic, J.L. (2010). Work design in situ: Understanding the role of occupational and organizational context. Journal of Organizational Behavior, 31, 351-360. doi: 10.1002/job.642

Ouweneel, E., Le Blanc, P.M., Schaufeli, W.B., \& Van Wijhe, C. (2012). Good morning, good day: A diary study on positive emotions, hope, and work engagement. Human Relations, 65, 1129-1154. doi: 10.1177/0018726711429382

Purcell, J. (2014). Disengaging from engagement. Human Resource Management Journal, 24, 241-254. doi: 10.1111/1748-8583.12046

QSR International (2010) NVivo Qualitative Data Analysis Software Version 9. [Computer Software] QSR International

Reio, T.G. and Sanders-Reio, J. (2011). Thinking about workplace engagement: Does supervisor and coworker incivility really matter?. Advances in Developing Human Resources, 13, 462-478. doi: 10.1177/1523422311430784

Rich, B.L., Lepine, J.A., \& Crawford, E.R. (2010). Job engagement: Antecedents and effects on job performance. Academy of Management Journal, 53, 617-635. doi:10.5465/AMJ.2010.51468988

Roe, R. ., \& Inceoglu, I. (2016). Measuring states and traits in motivation and emotion: A 
new model illustrated for the case of work engagement. In F. T. L. Leong, D. Bartram, F. M. Cheung, K. F. Geisinger, \& D. Iliescu (Eds). The ITC International Handbook of Testing and Assessment (pp. 63-88). Oxford: Oxford University Press.

Saks, A.M., \& Gruman, J.A. (2014). What do we really know about employee engagement?. Human Resource Development Quarterly, 25, 155-182. doi: 10.1002/hrdq.21187

Schaufeli, W. B. and Bakker, A. B. (2010). Defining and measuring work engagement: Bringing clarity to the concept. In A.B. Bakker and M.P. Leiter (Eds.), Work Engagement: A Handbook of Essential Theory and Research (pp. 10-24). New York: Psychology Press.

Schaufeli, W.B., Salanova, M., González-Romá, V., \& Bakker, A.B. (2002). The measurement of engagement and burnout: A two sample confirmatory factor analytic approach. Journal of Happiness Studies, 3, 71-92. doi: 10.1023/A:1015630930326

Shuck, B. (2011). Four emerging perspectives of employee engagement: An integrative literature review. Human Resource Development Review, 10, 304-328. doi: $10.1177 / 1534484311410840$

Shuck, B., \& T.S. Rocco, T.S. (2014). Human resource development and employee engagement. In C. Truss, R. Delbridge, K. Alfes, A. Shantz, \& E. Soane (Eds.), Employee Engagement in Theory and Practice (pp. 116-130). London: Routledge.

Shuck, M.B., Rocco, T.S., \& Albornoz, C.A. (2011). Exploring employee engagement from the employee perspective: implications for HRD. Journal of European Industrial Training, 35, 300-325. doi: 10.1108/03090591111128306

Shuck, B., Twyford, D., Reio, T.G., \& Shuck. A. (2014). Human resource development practices and employee engagement: Examining the connection with employee turnover 
intentions. Human Resource Development Quarterly, 25, 239-270. doi: 10.1002/ hrdq. 21190

Simbula, S. (2010). Daily fluctuations in teachers' well-being: A diary study using the job demands-resources model. Anxiety, Stress, and Coping, 23, 563-584. doi: $10.1080 / 10615801003728273$

Symon, G., \& Cassell, C. (2012). Qualitative Organizational Research: Core Methods and Current Challenges. London: Sage Publications.

Tadić, M., Bakker, A. B., \& Oerlemans, W. G. M. (2015). Challenge versus hindrance job demands and well-being: A diary study on the moderating role of job resources. Journal of Occupational and Organizational Psychology, 88, 702-725. doi: 10.1111/joop. 12094

Xanthopoulou, D., Bakker, A. B., Demerouti, E., \& Schaufeli, W. B. (2012). A diary study on the happy worker: How job resources relate to positive emotions and personal resources. European Journal of Work and Organizational Psychology, 21, 489-517. doi: 10.1080/1359432X.2011.584386

Yang, J., \& Diefendorff, J. M. (2009). The relations of daily counterproductive workplace behavior with emotions, situational antecedents, and personality moderators: A diary study in Hong Kong. Personnel Psychology, 62, 259-295. doi: 10.1111/j.17446570.2009.01138.x

Yin, R.K. (2009). Case Study Research: Design and Methods (4th ed.). Thousand Oaks, CA: Sage Publications. 
Table 1. Participant characteristics across the organizational settings

\begin{tabular}{|llllllll|}
\hline Organization & \multicolumn{2}{l}{ Manufacturing } & \multicolumn{2}{ll}{ Professional services } & \multicolumn{2}{l|}{ Public sector } & \multicolumn{2}{c|}{ Total } \\
& $\mathbf{1}$ & $\mathbf{2}$ & $\mathbf{3}$ & $\mathbf{4}$ & $\mathbf{5}$ & $\mathbf{6}$ & sample \\
\hline Sample Size & 21 & 16 & 22 & 20 & 26 & 19 & 124 \\
\% Male & 57 & 50 & 27 & 50 & 35 & 26 & 40 \\
Age (SD) & $39(12)$ & $36(11)$ & $35(13)$ & $34(9)$ & $45(11)$ & $45(9)$ & $39(11)$ \\
Mean Tenure (SD) & $9(8)$ & $11(11)$ & $8(8)$ & $6(5)$ & $10(8)$ & $11(6)$ & $9(8)$ \\
\% Managers & 38 & 50 & 45 & 57 & 31 & 37 & 42 \\
\% Fulltime & 95 & 94 & 82 & 85 & 50 & 80 & 80 \\
\hline
\end{tabular}




\section{Heightened Personal Role Engagement}

1. Task Resources

i. Task variety and challenge

a. Skill utilization and problem-solving

b. Responsibility and significance to one's self

c. Novelty and learning

ii. Task clarity and purpose

a. Clarity and significance to others

b. Personal contribution

2. Relational Resources

i. Perceived supervisory support
a. Feedback and recognition
b. Support and guidance
c. Coaching and development

ii. Perceived co-worker support

a. Support and co-operation

b. Feedback and recognition

c. Positive and energizing work climate

iii. Positive customer/client interactions
a. Co-operation
b. Positive feedback

3. Organizational Resources

$i$. Planning and progress

a. Prioritization

b. Achieving progress

ii. Self regulation and recovery within work
a. Breaking up the day
b. Utilizing flexible work practices/tools
c. Physiological regulation

\section{Challenge Demands}

i. Challenges from workloads/work pressures
a. A sense of urgency and time pressure
b. A sense of regularity and certainty of workload

\section{Personal Resources}
$i$. Developing feelings of competence

\section{Reduced Personal Role Engagement}

\section{Relational Hindrances}

$i$. From line managers
a. Unclear expectations of performance
b. Restrictive practices
c. Undermining behaviors
d. Aggressive/dismissive communication style

ii. From co-workers
a. Reluctance to help
b. Poor feedback/lack of recognition
c. Negative group climate
d. Violation of group norms

iii. Negative customer/client interaction
a. Lack of co-operation
b. Poor feedback

2. Organizational Hindrances

i. Hindrances from physical environment, systems and processes

a. Distractions

b. Inefficiencies or breakdowns in (technological) systems

c. Inefficiencies or breakdowns in decision-making processes

ii. Hindrances from workloads and work pressures

a. Excessive and conflicting demands

b. Having too little workloads and demands

3. Personal Hindrances

i. From non-work roles

ii. From personal health and wellbeing

iii. From feeling insecure and self-conscious

4. Lack of Task and Organizational Resources

i. A lack of task variety and challenge

a. Feelings of boredom

b. Feelings of psychological disconnection

ii. An inability to plan and prioritize tasks

iii. An inability to self-regulate energies

Figure 1. Final template for factors associated with heightened and reduced personal role engagement

Note: Themes are ordered by level of salience/prevalence in the interview data 
Heightened personal role engagement

\section{Reduced personal role engagement}

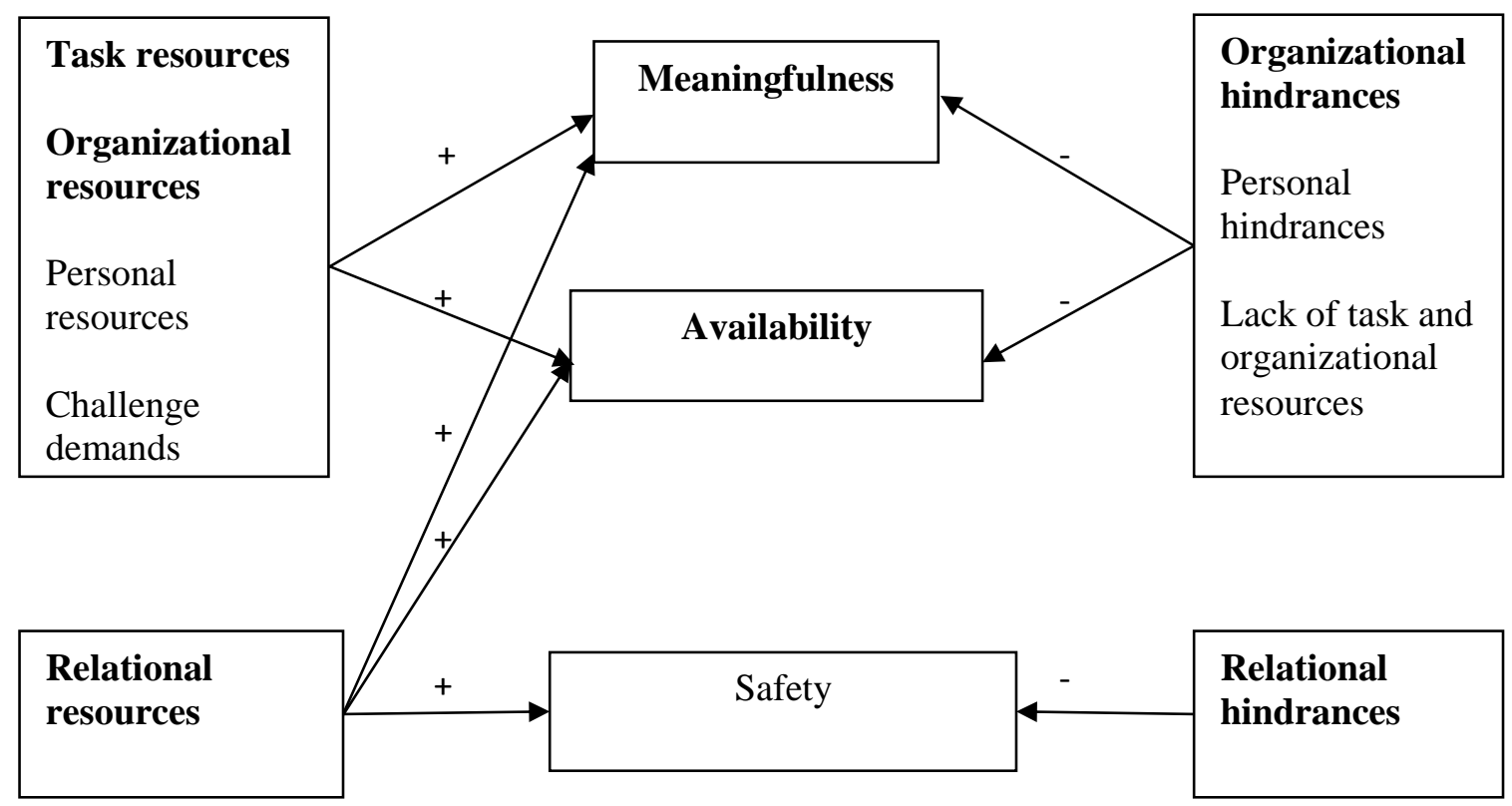

Note: Bold highlighted factors were the most strongly associated with engagement

Figure 2. Relationships between resources, demands and psychological conditions for heightened and reduced personal role engagement 